\title{
Risk of damage and desiccation cracking of construction materials based on raw earth
}

\author{
Ahmad El Hajjar ${ }^{1}$, Joanna Eid ${ }^{1,2, *}$, Tariq Ouahbi $^{1}$, and Said Taibi ${ }^{1}$ \\ ${ }^{1}$ LOMC/UMR CNRS 6294/University Le Havre, 76600 Le Havre, France \\ ${ }^{2}$ Civil engineering department/Holy Spirit University of Kaslik (USEK), 1200 Jounieh, Lebanon
}

\begin{abstract}
Nowadays, structures are mainly constructed using natural aggregates as sand and gravels. In the future, we would increasingly have to consider replacing them by more abundant and ecological natural materials such as raw earth. However, despite its many qualities (low gray energy, thermal and hygrometric isolation), this eco-material has some defects: cracking by desiccation. The later prevent its widespread diffusion. This study aims to understand the mechanisms of appearance and propagation of cracks in order to try to either prevent or repair it. To carry out this study, digital image correlation technique is used. It consists in performing free desiccation tests to follow the initiation and propagation of cracks, from the beginning of homogeneous strain until the appearance of discontinuity, in order to determine the strains tensor in the massif. In order to understand the origin of cracking, desiccation is studied for different boundary conditions and according to different intrinsic characteristics of the material.
\end{abstract}

\section{Introduction}

In our current society, raw earth presents an alternative as a non-energy consuming building material to deal with climatic and environmental issues. Despite these advantages, the use of this construction material remains somewhat limited due to harmful desiccation shrinkage, particularly in some drought areas. A significant shrinkage is likely to damage the structure due to cracking.

Cracking is mainly related to the presence of fine particles in the soil granulometry. These particles have a sensitivity to water, which results in major volume changes during their dehydration [1]. Cracks create brittle areas in the soil matrix and can alter its mechanical, physico-chemical and thermo-hydric properties. Kodikara et al. [2] showed that the cracking of clayey soils during desiccation is due to a tensile stress that develops in the material and induces its rupture once it exceeds its tensile strength. Desiccation modifies the microstructure configuration, orientation and specific surface area of the particles. The size of clay particles depends on the variation in soil suction [3].

\footnotetext{
* Corresponding author: joannaeid@usek.edu.lb
} 
To remedy this problem, it is essential to understand the evolution of the strain of the material during drying. This work presents an experimental study, which consists in carrying out free shrinkage tests on two types of clays (swelling and non-swelling) in order to identify the strain leading to cracking according to the imposed boundary conditions, the heterogeneity of the sample and its intrinsic characteristics.

\section{Materials and methods}

\subsection{Materials}

The materials used are on the one hand a Greek calcium montmorillonite and on the other hand a kaolinite called P300. Their geotechnical characteristics are presented in Table 1.

Table 1. Geotechnical characteristics of Greek calcic montmorillonite and P300 kaolinite [4].

\begin{tabular}{|c|c|c|c|}
\hline Characteristic & Symbol & Montmorillonite & Kaolinite \\
\hline \multirow{3}{*}{ Granulometry } & $<80 \mu \mathrm{m}(\%)$ & 100 & 100 \\
& $<2 \mu \mathrm{m}(\%)$ & 40 & 60 \\
& $\mathrm{~d}_{50}(\mu \mathrm{m})$ & 4 & 1,5 \\
\hline \multirow{3}{*}{ Plasticity } & $\mathrm{w}_{\mathrm{L}}(\%)$ & 170 & 40 \\
& $\mathrm{w}_{\mathrm{p}}(\%)$ & 60 & 21 \\
& $\mathrm{I}_{\mathrm{p}}(\%)$ & 110 & 19 \\
\hline Grain density & $\mathrm{Gs}\left(\mathrm{g} / \mathrm{cm}^{3}\right)$ & 2,73 & 2,65 \\
\hline
\end{tabular}

Figure 1 shows a scanning electron microscope (SEM) observation as well as an X-ray diffraction (XRD) analysis (in powder form) of this montmorillonite. We notice that it shows a rather complex texture. A SEM image and XRD analysis (oriented blade) of P300 kaolinite are presented in Figure 2. It should be noted that this clay, which is in the form of rigid hexagonal platelets of varying sizes between 1 and $2 \mu \mathrm{m}$, contains in addition to kaolinite (peaks at 7,18 and 3,58 $\AA$ ), illite (peaks at 10 and $5 \AA$ ) and quartz (peaks at 4,26 and $3,34 \AA)$.

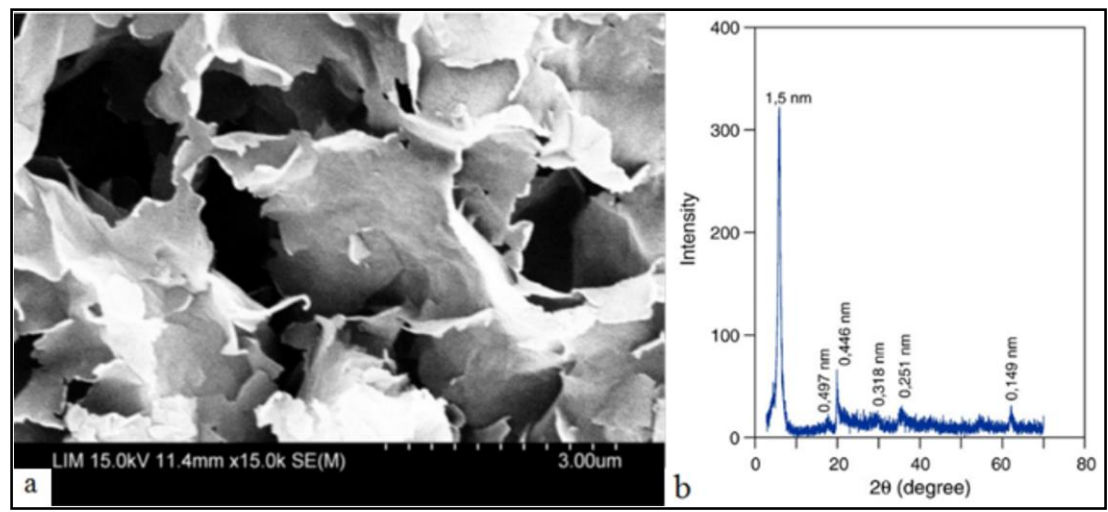

Fig. 1. SEM observation [5] (a) and XRD analysis of Greek calcic montmorillonite [6] (b). 


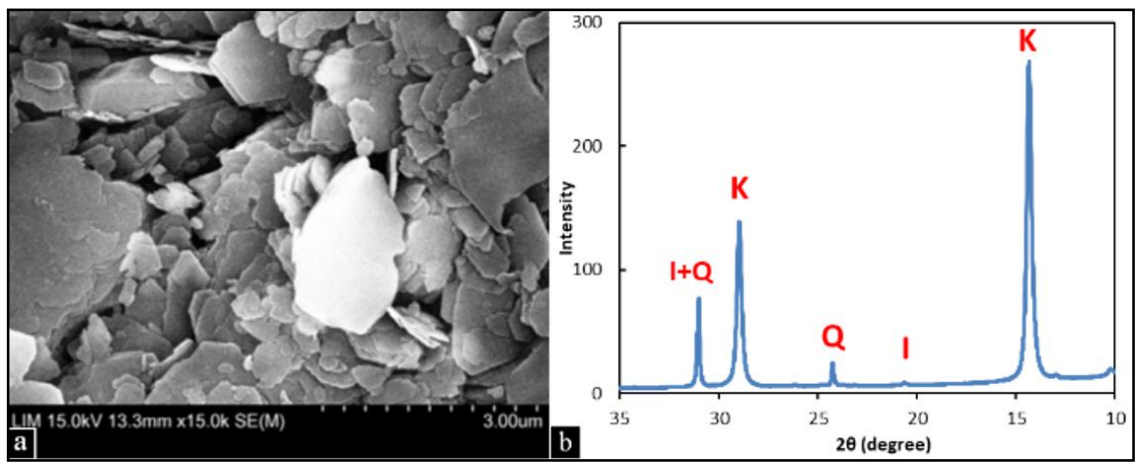

Fig. 2. SEM observation [5] (a) and XRD analysis of P300 kaolinite (b).

\subsection{Methods}

To study the effect of boundary conditions (external friction) on clay cracking, three different types of bases were used on a PVC plate:

a- Rough base: waterproof sandpaper having a very coarse grain "180" (commonly used for heavy stripping).

b- Semi-Rough base: waterproof sandpaper having a fine grain "400" (commonly used for finishing).

c- Smooth base: $1 \mathrm{~mm}$ thick virgin Teflon roll (static coefficient of friction $=0,08$ to 0,10 according to ASTM D1894).

All samples have dimensions of $20 \times 20 \mathrm{~cm}$ and a thickness of $8 \mathrm{~mm}$, and are wetted at an initial water content of $1,5 \mathrm{w}_{\mathrm{L}}\left(\mathrm{w}_{\mathrm{L}}\right.$ : Liquid Limit) for the kaolinite and $1,35 \mathrm{w}_{\mathrm{L}}$ for the montmorillonite. The selection of the initial moisture content is adopted so that the paste is normally consolidated and sufficiently consistent to facilitate its application. A speckled appearance, made with a white and black PVC powder, is required to allow the digital image correlation software to properly detect the difference between pixels. The entire experimental setup is controlled in terms of temperature $\left(\mathrm{T}=22,5{ }^{\circ} \mathrm{C}\right)$ and relative humidity $(\mathrm{RH}=18 \%)$.

During drying, a Canon 600D camera with a Macro lens took a monochromatic grayscale picture every 10 minutes. The lighting is performed using two fluorescent lamps (cold light) to prevent any disturbance of the ambient temperature. A schematic diagram of the assembly of this device is shown in Fig. 3.

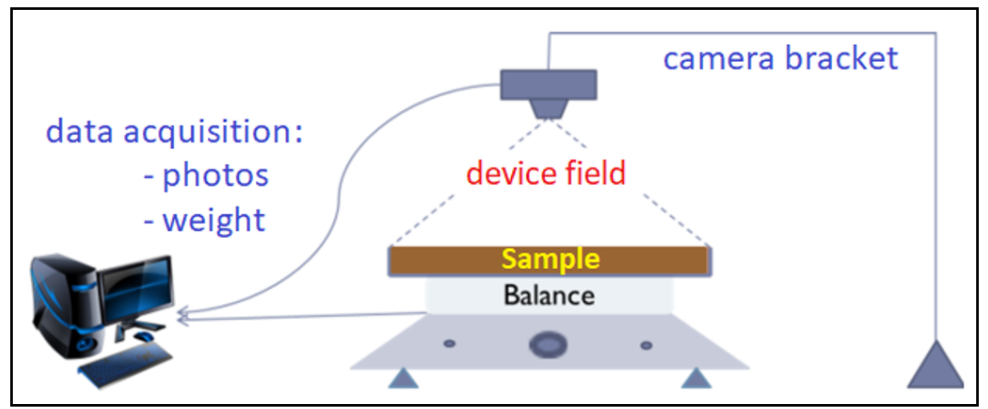

Fig. 3. Schematic diagram of the experimental device [7].

To study the strain of sample, a digital image correlation software "VIC-2D" was used. This software analyzes the difference between the pixels in the photos taken, in order to obtain a two-dimensional strain field of the sample surface. 
A list of the tests carried out is presented in Table 2:

Table 2. List of samples.

\begin{tabular}{|c|c|c|}
\hline Sample number & Type of clay & Type of base \\
\hline Sample 1 & Kaolinite & Rough \\
\hline Sample 2 & Kaolinite & Semi-Rough \\
\hline Sample 3 & Kaolinite & Smooth \\
\hline Sample 4 & Montmorillonite & Rough \\
\hline Sample 5 & Montmorillonite & Semi-Rough \\
\hline Sample 6 & Montmorillonite & Smooth \\
\hline
\end{tabular}

\section{Results and discussion}

Fig. 4 shows the final state of kaolinite samples (non-swelling clay) as a function of different boundary conditions (roughness of the base). The presence of cracks only for rough base highlights the effect of boundary conditions on the material's behavior during drying. Whereas in the case of swelling clay (montmorillonite), it is found that the material has cracked in all cases, independently of boundary conditions (Fig. 5). This is explained by the fact that montmorillonite particles play an important role in the shrinkage mechanism because of their low stiffness [8]. Furthermore, fine-grained soils are more sensitive to crack development than coarse-grained soils due to the presence of small pores that allow strong suction to develop. This suction generates internal stresses in the material that lead to its failure once they exceed its tensile strength [9]. Cracking of montmorillonite, even when friction in the base is negligible (case of smooth base), indicates that there are other intrinsic factors that act on montmorillonite paste by generating different types of solicitations (traction, compression, shear or torsion) resulting in material break-up. In order to identify the type of solicitation existent, it will be essential to complete this study with other tests by increasing the thickness of samples, which reduces edge effects and allows better monitoring of strain evolution.

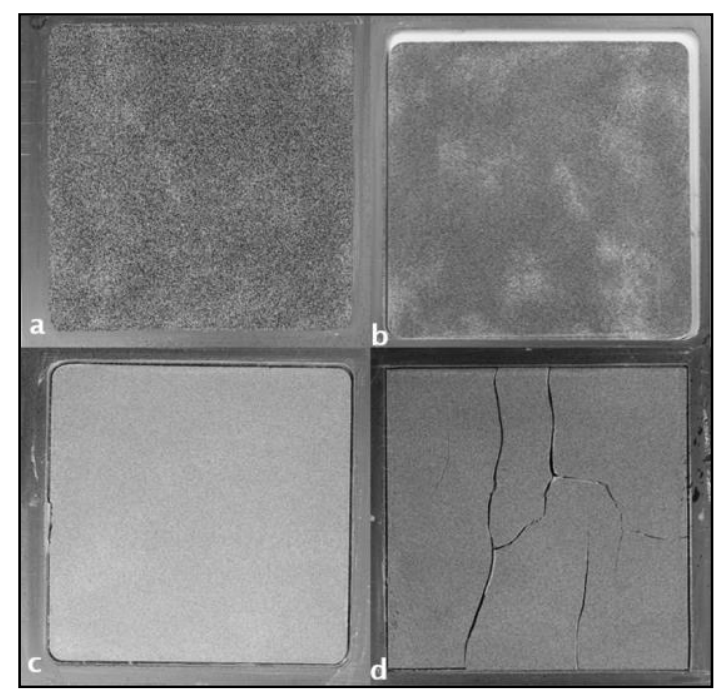

Fig. 4. Desiccation of kaolinite: (a) initial state (b) final state for a smooth base (c) for a semi-rough base (d) for a rough base. 
To provide a more detailed analysis of these tests, the strain fields of these two clays are previewed at the initiation of the first crack. In the case of kaolinite, we find that the first crack opened for a principal major strain $\varepsilon_{1}=4.6 \%$ (Fig. 6.a). As this value is positive, so the type of solicitation in this area is traction. However, this value is not maximum compared to other non-cracked areas $(9.4 \%)$, which indicates that the tensile stress is not the solicitation that led to the break-up of the material since it is still able to withstand a strain of higher than $4.6 \%$. Going to the principal minor strain (Fig. 6.b), we find that the first crack opened for $\varepsilon_{2}=1.5 \%$, which represents the maximum of minor strain. And since this strain is always positive, it was the simple shear that induced the initiation of this crack, knowing that the force required to tear off the particles is much greater than that required to slip the particles one against the other.

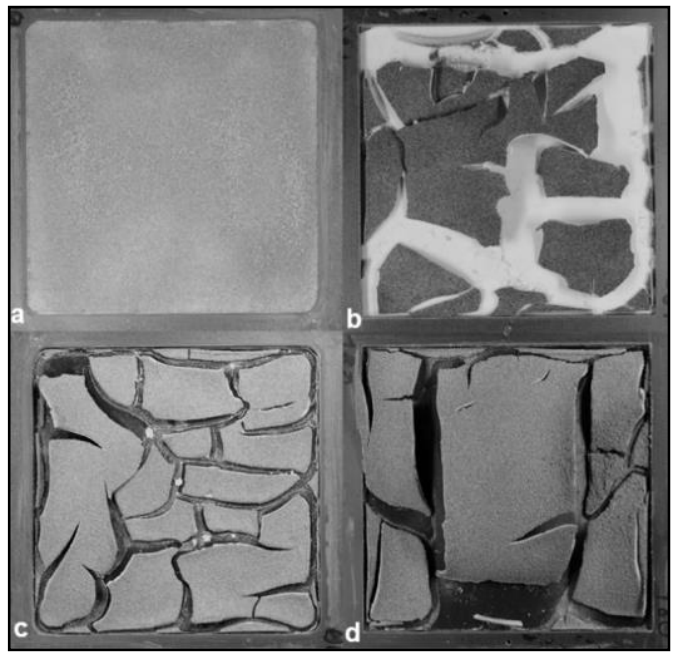

Fig. 5. Desiccation of montmorillonite: (a) initial state (b) final state for a smooth base (c) for a semirough base (d) for a rough base.

In the case of montmorillonite, we can see that the first crack opened for $\varepsilon_{1}=9.8 \%$ which is the maximum major strain at this time (Fig. 7.a), indicating that it is a tensile stress (caused by soil/base friction) which are responsible for the material break-up, once it has exceeded its tensile strength. Visualization of the principal minor strain confirms this hypothesis, seeing that it does not present any significant solicitation in the area of initiation of the first crack (Fig. 7.b).

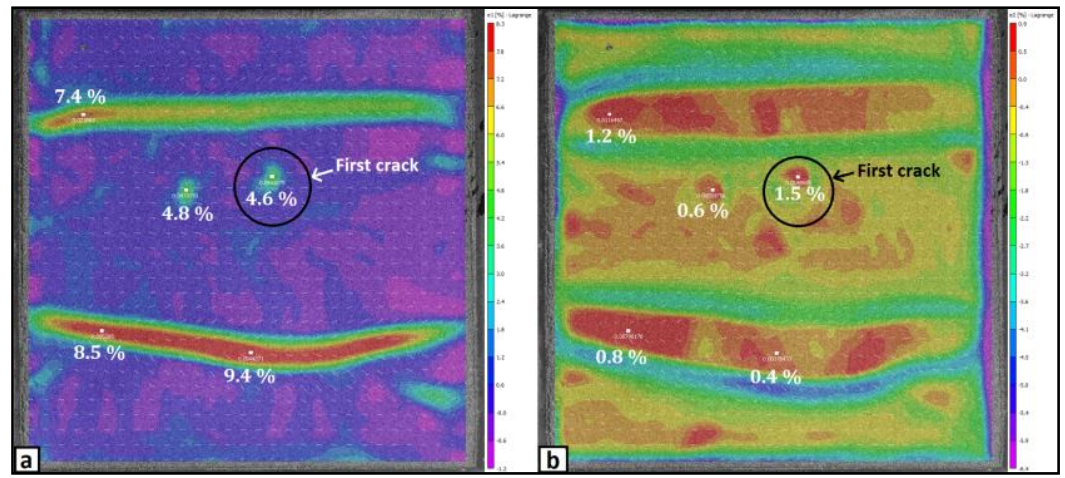

Fig. 6. Strain fields of kaolinite at the initiation of the first crack: (a) principal major strain (b) principal minor strain. 


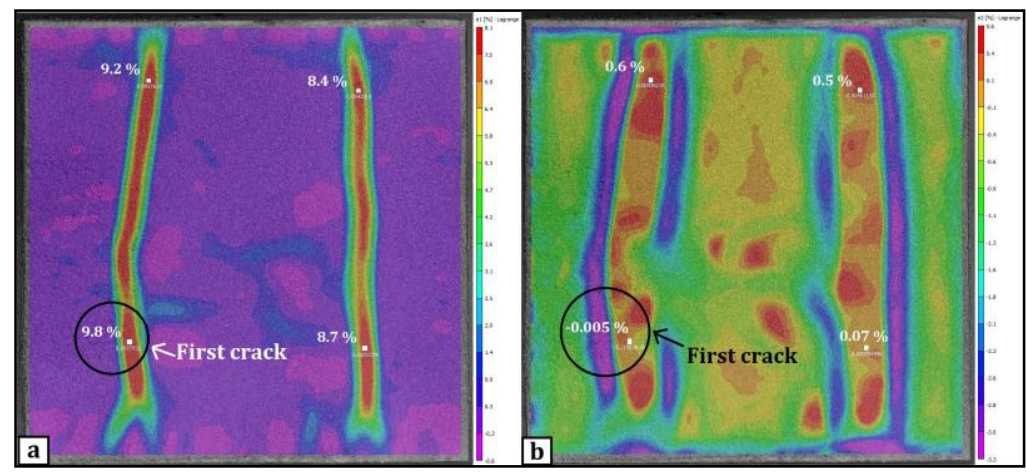

Fig. 7. Strain fields of montmorillonite at the initiation of the first crack: (a) principal major strain (b) principal minor strain.

\section{Conclusion}

Boundary conditions influence the cracking of a clay, but also the intrinsic characteristics (mineralogical, mechanical and hydric) of the material have a greater influence on its behavior. The effect of these characteristics is expressed by suction phenomenon which can generate tensile, compression, shear or torsional solicitations.

The digital image correlation allows us to identify the types of stress in the material. We notice that kaolinite P300 cracked by simple shear while montmorillonite cracked by traction. It is possible that a local discontinuity (which may be caused by a quartz grain existing in the P300 mineralogy) generated shear in this clay. An analysis of the porosity of the sample and the orientation of sheets at the edges of cracks as well as in an uncracked area will be required to confirm the influence of discontinuity on material break-up.

\section{References}

1. A. El Hajjar, P. Chauhan, N. Prime, P. Olivier, Effect of suction on the mechanical characteristics of uniformly compacted rammed earth, IOP Conference Series: Earth and Environmental Science, 143 (no. 1), 012045 (2018)

2. J.K. Kodikara, S.L. Barbour, D.G. Fredlund, Desiccation cracking of soil layers, Unsaturated soils for Asia, 90 (no. 5809), 139 (2000)

3. L.P. Wilding, D. Tessier, Genesis of Vertisols: Shrink-Swell Phenomena, Vertisols: their distribution, properties, classification and management, 18, 55-96 (1988)

4. J.M. Fleureau, S. Kheirbek-Saoud, R. Soemitro, S Taibi, Behavior of clayey soils on drying-wetting paths, Canadian Geotechnical Journal, 30 (no. 2), 287-296 (1993)

5. T. Hammad, Comportement des sédiments marins de grande profondeur, Ph.D. Thesis, Ecole Centrale de Paris (2010)

6. H. Souli, J.M. Fleureau, M. Ayadi, M. Besnard, Physicochemical analysis of permeability changes in the presence of zinc, Geoderma, 145 (no. 1-2), 1-7 (2008)

7. J. Eid, S. Taibi, J.M. Fleureau, M. Hattab, Drying, cracks and shrinkage evolution of a natural silt intended for a new earth building material, Construction and Building Materials, 86, 120-132 (2015)

8. X. Wei, M. Hattab, J. M. Fleureau, R. Hu, Micro-macro-experimental study of two clayey materials on drying paths, Bulletin of Engineering Geology and the Environment, 72 (no. 3-4), 495-508 (2013)

9. J. Eid, Elaboration d'un éco-géo-matériau à base de terre crue, Ph.D. Thesis, Université Le Havre Normandie (2016) 